\title{
Commentary: A tried-and-true method for producing the next generation of innovators
}

\author{
From the ${ }^{\mathrm{a} D e p a r t m e n t}$ of Cardiothoracic Surgery, Alfred Health, Melbourne, Australia; and ${ }^{\mathrm{b}}$ Department of Sur- \\ gery (School of Clinical Sciences at Monash Health), Monash University, Clayton, Australia and ${ }^{\mathrm{c}}$ Department \\ of Cardiothoracic Surgery, Monash Health, Clayton, Australia. \\ Disclosures: Authors have nothing to disclose with regard to commercial support. \\ Received for publication Aug 16, 2019; accepted for publication Aug 19, 2019; available ahead of print Sept 27, \\ 2019. \\ Address for reprints: Julian A. Smith, MBBS, MS, MSurgEd, FRACS, FACS, Department of Surgery, Level 5 \\ Block E, Monash Medical Centre, 246 Clayton Rd, Clayton 3168, Australia (E-mail: Julian.Smith@monash. \\ edu). \\ J Thorac Cardiovasc Surg 2020;159:588-9 \\ $0022-5223 / \$ 36.00$ \\ Copyright (c) 2019 by The American Association for Thoracic Surgery \\ https://doi.org/10.1016/j.jtcvs.2019.08.018
}

William Y. Shi, MBBS, PhD, ${ }^{a}$ and Julian A. Smith, MBBS, MS, MSurgEd, FRACS, FACS ${ }^{\mathrm{b}, \mathrm{c}}$

A number of cardiothoracic surgery training paradigms from around the world have been highlighted in recent issues of the Journal. ${ }^{1-5}$ In this issue, Wick and colleagues ${ }^{6}$ provide a detailed insight into cardiac surgery training in Germany.

Germany has a rich history in cardiac surgery and continues to be a major innovator of our specialty. Through its outstanding training system, Germany has produced numerous giants of cardiac surgery. In recent years, its experience in minimally-invasive and transcatheter therapies have laid the foundation for its dissemination worldwide.

The German system is unique in that training is based at individual centers. Prospective trainees apply directly to these centers and spend almost all their training at one institution. Trainee progression and graduation is at the respective department's discretion. This is in contrast to training schemes from the United States, United Kingdom, and our own in Australia and New Zealand (ANZ), whereby training is-to varying extents-governed by a central body that provides external direction and oversight. Although a centralized system may ostensibly standardize training delivery, in practice, the German approach may allow centers to tailor training to the strengths and nuances of departments.

In Germany, there exists a robust theoretical and practical curriculum to guide training. The provision of rotations in the intensive care unit and emergency department is commendable, as these experiences are crucial in developing well-rounded surgeons. Our own system in ANZ has attempted to incorporate intensive care unit and cardiology terms into training. The German curriculum requires that the trainee performs 100 "pump cases" as the operator. It does not specify the number of component procedures (conduit harvest, sternotomy, cannulation, closure, etc), which we have found to be useful in monitoring junior trainees' progress. comfortable in independent practice. practice.

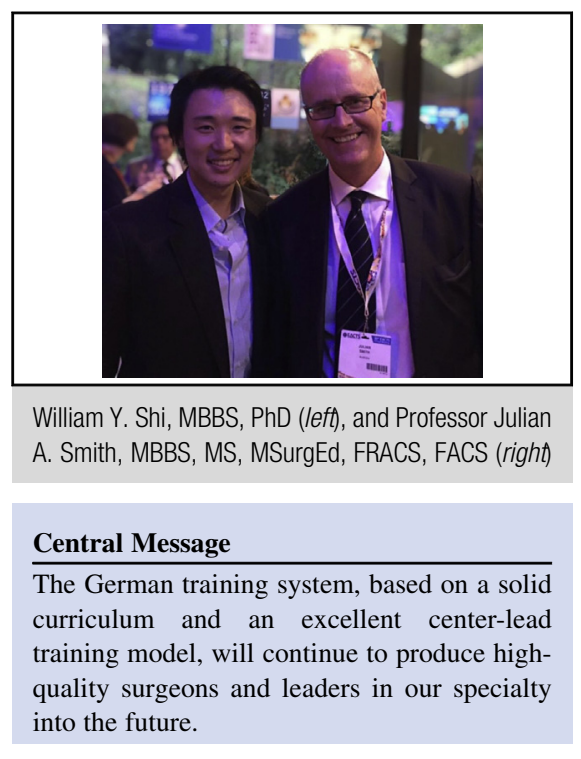

See Article page 579

Like other training systems from around the world, providing trainees in Germany with adequate experience as the operator remains a challenge in the face of greater patient complexity, time pressures, and limited resources. Wick and colleagues ${ }^{6}$ report that final-year trainees performed a mean of 30 "pump cases," with only $18 \%$ of sixth-year trainees meeting the requirement of 100 cases. These figures suggest that in the German system there may be a lag period between board certification and being

This phenomenon is not uncommon worldwide, whereby supervision by senior surgeons occurs before juniors becoming fully independent. In ANZ, graduating surgeons typically spend 1 to 2 further years undertaking postgraduation fellowship training locally or abroad before taking up a consultant position, which demands a substantial deal of independence both clinically and operatively without ubiquitous senior surgeon oversight. The question remains whether further training post-certification should be seen as a "rite of passage" or if this training should be delivered earlier such that board certification permits the immediate commencement of competent and confident independent

The German training system in cardiac surgery is based on a solid curriculum and an excellent center-lead training model, and it will undoubtedly continue to produce 
high-quality surgeons and leaders in our specialty for years to come.

\section{References}

1. Shapira OM, Sahar G, Raanani E. Cardiothoracic surgery training in Israel: a critical look at the past, aiming for a better future. J Thorac Cardiovasc Surg. 2016; 151:1508-15.

2. Noly PE, Rubens FD, Ouzounian M, Quantz M, Shao-Hua W, Pelletier M, et al. Cardiac surgery training in Canada: current state and future perspectives. J Thorac Cardiovasc Surg. 2017;154:998-1005.
3. Rocha RV, Almeida RMS. Cardiac surgery residency in Brazil: how to deal with the challenges of this unique specialty. J Thorac Cardiovasc Surg. 2018;156: 2227-32.

4. Shi WY, Oldfield Z, Tam R, Cochrane AD, Smith JA. Cardiothoracic surgery training in Australia and New Zealand. J Thorac Cardiovasc Surg. 2018;156: 718-25.

5. Zakkar M, Benedetto U, Angelini GD, Murphy G, Shah R, Jahangiri M, et al Cardiothoracic surgery training in the United Kingdom. J Thorac Cardiovasc Surg. 2019;157:1948-55.

6. Wick A, Beckmann A, Nemeth A, Conradi L, Schaefer A, Reichenspurner H, et al Cardiac surgery residents training in Germany-Status quo and future prospects. J Thorac Cardiovasc Surg. 2020;159:579-87. 